\title{
Spoilage potential of Pseudomonas species isolated from goat milk
}

\author{
T. M. Scatamburlo, ${ }^{*}$ A. K. Yamazi, ${ }^{*}$ V. Q. Cavicchioli, ${ }^{*}$ F. A. Pieri, ${ }^{*} \dagger$ and L. A. Nero*1 \\ *Universidade Federal de Viçosa, Departamento de Veterinária, Campus UFV, 36570 900, Viçosa, MG, Brazil \\ †Universidade Federal de Juiz de Fora, Departamento de Ciências Básicas da Saúde, Campus Governador Valadares, 35020220 , \\ Governador Valadares, MG, Brazil
}

\begin{abstract}
Pseudomonas spp. are usually associated with spoilage microflora of dairy products due to their proteolytic potential. This is of particular concern for protein-based products, such as goat milk cheeses and fermented milks. Therefore, the goal of the present study was to characterize the proteolytic activity of Pseudomonas spp. isolated from goat milk. Goat milk samples ( $\mathrm{n}=$ 61) were obtained directly from bulk tanks on dairy goat farms $(\mathrm{n}=12)$, and subjected to a modified International Organization for Standardization (ISO) protocol to determine the number and proteolytic activity of Pseudomonas spp. Isolates $(\mathrm{n}=82)$ were obtained, identified by PCR, and subjected to pulsed-field gel electrophoresis with $\mathrm{XbaI}$ macro-restriction. Then, the isolates were subjected to PCR to detect the alkaline protease gene $(a p r)$, and phenotypic tests were performed to check proteolytic activity at $7^{\circ} \mathrm{C}, 25^{\circ} \mathrm{C}$, and $35^{\circ} \mathrm{C}$. Mean Pseudomonas spp. counts ranged from 2.9 to $4.8 \log \mathrm{cfu} / \mathrm{mL}$, and proteolytic Pseudomonas spp. counts ranged from 1.9 to $4.6 \log \mathrm{cfu} / \mathrm{mL}$. All isolates were confirmed to be Pseudomonas spp., and 41 were identified as Pseudomonas fluorescens, which clustered into 5 groups sharing approximately $82 \%$ similarity. Thirty-six isolates (46.9\%) were positive for the apr gene; and $57(69.5 \%)$ isolates presented proteolytic activity at $7^{\circ} \mathrm{C}, 82(100 \%)$ at $25^{\circ} \mathrm{C}$, and $64(78 \%)$ at $35^{\circ} \mathrm{C}$. The isolates were distributed ubiquitously in the goat farms, and no relationship among isolates was observed when the goat farms, presence of apr, pulsotypes, and proteolytic activity were taken into account. We demonstrated proteolytic activity of Pseudomonas spp. present in goat milk by phenotypic and genotypic tests and indicated their spoilage potential at distinct temperatures. Based on these findings and the ubiquity of Pseudomonas spp. in goat farm environments, proper
\end{abstract}

Received August 15, 2014.

Accepted November 2, 2014.

${ }^{1}$ Corresponding author: nero@ufv.br monitoring and control of Pseudomonas spp. during production are critical.

Key words: Pseudomonas, spoilage, proteolysis, goat milk

\section{INTRODUCTION}

Goat milk and derivative products are considered high-quality products by the dairy industry because of their biochemical and organoleptic characteristics. Among consumers, goat milk is considered a healthy food (Haenlein, 2004), and the characteristics of its components allow production of highly priced dairy products, such as cheeses, yogurts, and a variety of other fermented products (Pandya and Ghodke, 2007; Scintu and Piredda, 2007).

As with any other food of animal origin, goat milk is susceptible to microbial contamination during production, which can jeopardize its quality and safety (Chambers, 2002). In this context, keeping the product at low temperatures during production is important for preventing bacterial growth during storage and transport and avoiding the development of most spoilage microorganisms (Quigley et al., 2013). Refrigeration is usually adopted for this purpose, but must be applied considering adequate conditions of the equipment, temperature, and storage period. Otherwise, microbial counts, especially those of the psychrotrophic microbiota, can increase dramatically, thus resulting in poor quality goat milk and its dairy products (Sorhaug and Stepaniak, 1997; Yamazi et al., 2013).

Pseudomonas spp. is a relevant psychrotrophic genus responsible for spoilage of raw milk, including goat milk (Dufour et al., 2008; Arslan et al., 2011; Chen et al., 2011). Pseudomonas spp. have high genetic diversity and metabolic versatility, allowing them to survive in different environments, such as soil, water, and air. These characteristics allow them to survive on the utensils and equipment used in the dairy production chain, such as pipelines, bulk tanks, milking machines, and animal production environment (Simões et al., 2010). Pseudomonas fluorescens, Pseudomonas aeruginosa, and Pseudomonas putida are the main Pseudomonas 
species found in the dairy chain and are responsible for the production of proteolytic enzymes that are resistant to high temperatures and cause spoilage, even in processed dairy products (Rajmohan et al., 2002; Marchand et al., 2009). The metalloprotease AprX is one of the enzymes produced by Pseudomonas spp., and it is of particular interest to the dairy industry due to its specific spoilage activity in casein, which results in significant modifications to the physico-chemical and organoleptic properties of raw milk (Dufour et al., 2008).

The goal of the present study was to characterize the proteolytic potential and genetic diversity of Pseudomonas spp. present in the spoilage microbiota of raw goat milk, and to report information to support strategies to control their contamination and growth.

\section{MATERIALS AND METHODS}

\section{Goat Milk Samples and Pseudomonas spp. Counts}

Raw milk goat samples $(\mathrm{n}=61)$ were collected directly from bulk tanks on 12 dairy goat farms located in Minas Gerais State, Brazil. At least 3 samples were obtained from each farm from different milking procedures. All samples were refrigerated during transport to the laboratory, where they were diluted 10 -fold in $0.85 \%$ $\mathrm{NaCl}$ (wt/vol; Wehr and Frank, 2004) and subjected to microbial analysis to determine the counts of Pseudomonas spp. and proteolytic Pseudomonas spp. using a modified protocol of ISO/TS 11.059 (ISO, 2009).

Aliquots $(0.1 \mathrm{~mL})$ of selected dilutions were plated in duplicate onto the surface of Pseudomonas agar (Oxoid Ltd., Basingstoke, UK) supplemented with penicillin (100,000 IU/L, Sigma Aldrich, St. Louis, MO), pimaricin $(0.01 \mathrm{~g} / \mathrm{L}$, Sigma), and sterile skim milk [10\%, vol/ vol, previously prepared with Molico skim powder milk (Nestlé, São Paulo, Brazil) diluted in sterile water]. The plates were incubated at $25^{\circ} \mathrm{C}$ for $72 \mathrm{~h}$, and then all colonies were counted based on presence (proteolytic Pseudomonas spp.) or absence (Pseudomonas spp.) of a proteolytic halo.

From each sample, one plate that had 30 to 300 colonies was selected, and $10 \%$ of the colonies were streaked onto Pseudomonas agar plates (Oxoid), incubated at $25^{\circ} \mathrm{C}$ for $24 \mathrm{~h}$, and subjected to Gram staining, assessment of oxidase production, and a glucose fermentation test (Downes and Ito, 2001). Pseudomonas spp. were preliminarily identified as gram-negative rods, oxidase positive, and able to use glucose, according ISO (2009). Based on these results, Pseudomonas spp. and proteolytic Pseudomonas spp. counts were expressed as colony forming units per milliliter for each sample and converted to $\log _{10}$ for data presentation.

\section{Pseudomonas spp. Identification and Fingerprinting}

Isolates that were preliminary identified as Pseudomonas spp. $(\mathrm{n}=82)$ were subjected to molecular analysis to confirm their identification and genetic profiles. Polymerase chain reaction was conducted to confirm the isolates as belonging to the genus Pseudomonas and to identify the species $P$. fluorescens. Single colonies from each isolate were transferred to trypticase soy broth (Oxoid) and incubated at $25^{\circ} \mathrm{C}$ for $24 \mathrm{~h}$. The aliquots were subjected to DNA extraction using the Wizard Genomic DNA Purification Kit (Promega Corporation, Madison, WI). The concentration of DNA was estimated by spectrophotometry (NanoDrop Lite, Thermo Scientific, Wilmington, DE).

Pseudomonas spp. were confirmed by checking a genus-specific region of the $16 \mathrm{~S}$ DNA region, as previously described by Spilker et al. (2004), and using the primers PA-GS-F (GACGGGTGAGTAATGCCTA) and PA-GS-R (CACTGGTGTTCCTTCCTATA). The PCR reactions consisted of $12.5 \mu \mathrm{L}$ of Go Taq Green Master Mix $2 \times$ (Promega), $1 \mu \mathrm{L}$ of extracted DNA $(\sim 50-100 \mathrm{ng} / \mu \mathrm{L}), 10 \mathrm{pmol}$ of each primer, and ultrapure water (Promega) to bring the final volume to 25 $\mu \mathrm{L}$. Amplification conditions were 1 cycle at $95^{\circ} \mathrm{C}$ for $2 \mathrm{~min}, 25$ cycles of $94^{\circ} \mathrm{C}$ for $20 \mathrm{~s}, 54^{\circ} \mathrm{C}$ for $20 \mathrm{~s}$, and $72^{\circ} \mathrm{C}$ for $40 \mathrm{~s}$, and a final extension step at $72^{\circ} \mathrm{C}$ for $1 \mathrm{~min}$. The PCR products were electrophoresed in a $1.5 \%$ (wt/vol) agarose gel in 0.5× Tris-borate EDTA, stained in a GelRed bath (Biotium Inc., Hayward, CA), and visualized using a transilluminator LPIX (Locus Biotecnologia, São Paulo, Brazil). Amplicons of 618 bp were considered typical for Pseudomonas genus.

A region from DNA $16 \mathrm{~S}$ specific for P. fluorescens was investigated using the primers 16SPSEfluF (TGCATTCAAAACTGACTG) and 16SPSER (AATCACACCGTGGTAACCG; Scarpellini et al., 2004). The PCR reactions consisted of $12.5 \mu \mathrm{L}$ of Go Taq Green Master Mix $2 \times$ (Promega), $1 \mu \mathrm{L}$ of DNA ( $\sim 50-100$ $\mathrm{ng} / \mu \mathrm{L}), 10 \mathrm{pmol}$ of each primer, and ultra-pure water (Promega) to bring the final volume to $25 \mu \mathrm{L}$. Amplification conditions were 1 cycle of $94^{\circ} \mathrm{C}$ for $2 \mathrm{~min}, 30$ cycles of $94^{\circ} \mathrm{C}$ for $1 \mathrm{~min}, 60^{\circ} \mathrm{C}$ for $30 \mathrm{~s}$, and $72^{\circ} \mathrm{C}$ for 1 min, and a final extension step at $72^{\circ} \mathrm{C}$ for $7 \mathrm{~min}$. The PCR products were electrophoresed in a $1.5 \%$ (wt/vol) agarose gel in $0.5 \times$ Tris-borate EDTA, stained in a GelRed bath (Biotium), and visualized using a transilluminator LPIX (Locus). Amplicons of approximately 800 bp were considered typical for P. fluorescens.

Genetic profiles of the isolates were obtained by pulsed-field gel electrophoresis (PFGE). Isolated colonies from each Pseudomonas spp. isolate were transferred to trypticase soy broth (Oxoid) and incubated at $25^{\circ} \mathrm{C}$ to obtain a culture with an optical density of $1(\lambda$ 
$=590 \mathrm{~nm}$ ). Then, $400-\mu \mathrm{L}$ aliquots of each culture were transferred to micro-tubes and $5 \mu \mathrm{L}$ of lysozyme $(20$ $\mathrm{mg} / \mathrm{mL}$, Sigma) and $5 \mu \mathrm{L}$ of proteinase $\mathrm{K}(1 \mathrm{mg} / \mathrm{mL}$, Sigma) were added, followed by incubation at $37^{\circ} \mathrm{C}$ for $15 \mathrm{~min}$. Plugs were prepared with agarose and digested with $5 \mathrm{U}$ of $\mathrm{Xba \textrm {I }}$ (Promega) at $37^{\circ} \mathrm{C}$ for $7 \mathrm{~h}$. Macrorestriction products were separated in $1.5 \%$ (wt/vol) agarose gels in $0.5 \times$ Tris-borate EDTA, by PFGE in a CHEF-DRIII (Bio-Rad Laboratories, Hercules, CA) using the following parameters: $17 \mathrm{~h}, 6 \mathrm{~V} / \mathrm{cm}$ gradient, $120^{\circ}$ angle, and $2-$ to $20-\mathrm{s}$ interpooled pulses, at $12^{\circ} \mathrm{C}$. The gels were stained in a GelRed bath (Biotium) and visualized using a transilluminator LPIX (Locus). Profiles were analyzed using BioNumerics 6.6 (Applied Maths, Ghent, Belgium) with $5 \%$ as the tolerance for the Dice similarity of bands. The unweighted pair group method with arithmetic mean (UPGMA) was used for clustering and dendrogram construction.

\section{Proteolytic Potential}

The PCR was performed on the DNA obtained previously from all isolates to detect a specific region of the alkaline protease gene $(\boldsymbol{a p r})$ that is responsible for AprX production by Pseudomonas spp. using the primers FP apr I (TAYGGBTTCAAYTCCAAYAC) and RF apr II (VGCGATSGAMACRTTRCC), according to the protocol described by Bach et al. (2001). Amplification reactions contained $12.5 \mu \mathrm{L}$ of Go Taq Green Master Mix $2 \times$ (Promega), $1 \mu \mathrm{L}$ of DNA $(\sim 50-100$ $\mathrm{ng} / \mu \mathrm{L}), 10 \mathrm{pmol}$ of each primer, and ultra-pure water (Promega) to bring the final volume to $25 \mu \mathrm{L}$. Amplification conditions were 1 cycle of $95^{\circ} \mathrm{C}$ for $5 \mathrm{~min}, 30$ cycles of $94^{\circ} \mathrm{C}$ for $30 \mathrm{~s}, 53^{\circ} \mathrm{C}$ for $30 \mathrm{~s}$, and $72^{\circ} \mathrm{C}$ for $20 \mathrm{~s}$, and a final extension step at $72^{\circ} \mathrm{C}$ for $10 \mathrm{~min}$. The PCR products were electrophoresed in a $1.5 \%$ (wt/vol) agarose gel in $0.5 \times$ Tris-borate EDTA, stained in a GelRed bath (Biotium), and visualized using a transilluminator LPIX (Locus). Amplicons of $194 \mathrm{bp}$ were considered typical for apr.

The proteolytic activity of isolates was verified by inoculating $1-\mu \mathrm{L}$ aliquots of cultures onto the surface of trypticase soy agar (Oxoid) supplemented with sterile skim milk (10\%, vol/vol, prepared as previously described). The plates were incubated at $7^{\circ} \mathrm{C}$ for 10 $\mathrm{d}, 25^{\circ} \mathrm{C}$ for $3 \mathrm{~d}$, or $35^{\circ} \mathrm{C}$ for $2 \mathrm{~d}$. Then, $8 \mathrm{~mL}$ of $1 \%$ (vol/vol) $\mathrm{HCl}$ was added to the plates for $1 \mathrm{~min}$ and discarded. The presence of halos in the inoculated area was a positive result for the proteolytic activity of the isolates (Downes and Ito, 2001).

\section{RESULTS AND DISCUSSION}

Table 1 shows the mean values and standard deviations for counts of presumptive Pseudomonas spp. and proteolytic Pseudomonas spp. obtained from goat milk samples from each dairy farm included in the study, as well as mean percentages of the proteolytic colonies based on the total Pseudomonas spp. counts by farm. Mean Pseudomonas spp. counts ranged from 3.0 to 4.8 $\log \mathrm{cfu} / \mathrm{mL}$, whereas mean proteolytic Pseudomonas spp. counts ranged from 1.9 to $4.6 \log \mathrm{cfu} / \mathrm{mL}$. We detected no direct relationship between the presence or number of proteolytic Pseudomonas spp. and the total number of Pseudomonas spp. Milk samples from farm 11 had relatively high mean Pseudomonas spp. counts $(4.7 \log \mathrm{cfu} / \mathrm{mL})$ but only $6.4 \%$ were proteolytic, whereas farm 10 presented a relatively low mean count (3.0 log cfu/mL), with $50.3 \%$ being proteolytic (Table $1)$.

Even though Pseudomonas species are known to be common components of raw goat milk microbiota (Quigley et al., 2013), there is a lack of information regarding their typical counts in this product. Because goat milk production chains are similar to cow milk production chains, they share the main sources of contamination by different microbial groups, including Pseudomonas spp. Mean counts of Pseudomonas spp. vary in cow milk from $5.0 \log \mathrm{cfu} / \mathrm{mL}$ just after milking to $5.2 \mathrm{log}$ $\mathrm{cfu} / \mathrm{mL}$ after storage in a bulk tank (Fagundes et al., 2006), which is similar to the highest mean values of Pseudomonas spp. obtained in the present study from raw goat milk from bulk tanks (Table 1). Pseudomonas spp. counts varied from 1.0 to $6.6 \mathrm{log} \mathrm{cfu} / \mathrm{mL}$ in samples of cow milk obtained from bulk tanks from different dairy farms (Pinto et al., 2006), demonstrating a large variation in the contamination of milk by this group. Based on the obtained data, variation in Pseudomonas spp. counts by goat farm can be observed (Table 1). These results also indicated the relevant participation of proteolytic strains in the Pseudomonas spp. microbiota of goat milk (Table 1): in 37 goat milk samples $(60.1 \%)$, proteolytic colonies represented more than $50 \%$ of the total Pseudomonas spp. counts (data not shown). Once Pseudomonas spp. can produce spoilage enzymes, their presence at such levels in goat milk is a concern (Marchand et al., 2009; Chen et al., 2011).

All isolates $(\mathrm{n}=82)$ were confirmed as belonging to the Pseudomonas genus, with 41 being identified as $P$. fluorescens (Figure 1). After enzymatic digestion with $X b a \mathrm{I}$, isolates were clustered into 5 groups sharing approximately $82 \%$ similarity (Figure 1 ). Based on PFGE analysis, the random distribution of Pseudomonas spp. strains in different dairy goat farms included in the study was identified. Specifically, identical strains were isolated from different farms, and one farm had Pseudomonas spp. strains with different pulsotypes. These results demonstrate the ubiquitous nature of Pseudomonas spp. in dairy goat farms, highlighting their rel- 
Table 1. Mean values and standard deviations of presumptive Pseudomonas spp. and proteolytic Pseudomonas spp. in goat milk samples obtained from bulk tanks of 12 dairy goat farms located in Minas Gerais state, Brazil, and mean percentages of proteolytic colonies considering the total Pseudomonas counts

\begin{tabular}{lcccc}
\hline & & \multicolumn{2}{c}{$\begin{array}{c}\text { Pseudomonas spp. } \\
(\log \mathrm{cfu} / \mathrm{mL})\end{array}$} & $\begin{array}{c}\text { Mean percentage } \\
\text { of proteolytic } \\
\text { colonies }\end{array}$ \\
\cline { 2 - 4 } Farm & $\begin{array}{c}\text { No. of } \\
\text { samples }\end{array}$ & Total & Proteolytic & 40.4 \\
\hline 1 & 4 & $3.9 \pm 0.7$ & $3.4 \pm 0.4$ & 36.1 \\
3 & 4 & $4.3 \pm 0.5$ & $3.6 \pm 0.8$ & 58.0 \\
4 & 10 & $4.0 \pm 0.7$ & $3.7 \pm 1.1$ & 58.0 \\
5 & 3 & $4.5 \pm 0.4$ & $4.2 \pm 0.6$ & 61.1 \\
6 & 9 & $3.9 \pm 0.7$ & $3.6 \pm 0.8$ & 6.2 \\
7 & 5 & $3.1 \pm 0.9$ & $1.9 \pm 0.2$ & 72.1 \\
8 & 5 & $3.0 \pm 0.3$ & $2.7 \pm 0.7$ & 77.7 \\
9 & 5 & $4.8 \pm 1.1$ & $4.6 \pm 1.3$ & 50.3 \\
10 & 5 & $3.4 \pm 1.0$ & $3.2 \pm 0.9$ & 6.4 \\
11 & 5 & $3.0 \pm 0.8$ & $2.7 \pm 1.0$ & 42.1 \\
Mean & 3 & $4.7 \pm 1.2$ & $2.9 \pm 0.2$ & 51.0 \\
\hline
\end{tabular}

evance as natural contaminants of goat milk (Quigley et al., 2013). In a similar study conducted with cow milk, P. fluorescens and P. putida were the main Pseudomonas species identified from different samples and points during production. Additionally, high genetic diversity is observed among isolates by ribotyping, demonstrating diversity in the origin of contamination within the environment (Dogan and Boor, 2003). Isolates clustered by PFGE did not show an association with the identified species (P. fluorescens) or to apr and proteolytic activity (data not shown), thus demonstrating the diversity of Pseudomonas spp. in the dairy goat farms included in the present study.

Table 2 shows the frequencies of isolates that harbored apr, as well as the results for proteolytic activity after incubation at different temperatures. The apr gene was detected in 32 isolates, and proteolytic activity was observed at all tested temperatures (at different frequencies). Even apr-negative isolates had proteolytic activity, indicating that proteases other than AprX were produced. Among Pseudomonas species, apr is usually studied to assess the proteolytic and spoilage potential of isolates (Bach et al., 2001; Marchand et al., 2009). Martins et al. (2005) extracted total DNA from samples of raw milk and studied apr to assess the spoilage potential of the microbiota due to the relevance of $\mathrm{AprX}$ in casein degradation during storage. In addition to AprX being considered the most important proteolytic enzyme associated with milk spoilage, other proteases can be produced by Pseudomonas spp., as described here (Table 2) and in other studies (Rajmohan et al., 2002; Chen et al., 2003; Hantsis-Zacharov and Halpern, 2007; Marchand et al., 2009; Samarzija et al., 2012). This highlights the relevance of controlling contamination by this genus in dairy product production.
Independent of the presence of the apr gene, the obtained data demonstrate protease production by the tested isolates at different temperatures (Table 2). This is a relevant finding because it confirms the ability of Pseudomonas spp. to produce such enzymes under the psychrotrophic conditions usually observed in the dairy production chain, even for goat milk. The Brazilian Ministry of Agriculture recommends a temperature of $7^{\circ} \mathrm{C}$ as an alternative to refrigeration at $4^{\circ} \mathrm{C}$ for storing milk in dairy farms in immersion tanks (Brasil, 2011). This procedure involves submerging milk cans in tanks filled with cold water, keeping them at an average temperature of $7^{\circ} \mathrm{C}$ (Perin et al., 2012). Even though this procedure has been indicated for the storage of raw milk produced by cows, it is widely used on dairy goat farms, because the current Brazilian legislation for goat milk does not specify temperatures or equipment for this purpose (Brasil, 2000). Based on our results, proteolytic Pseudomonas spp. were able to produce proteases at $7^{\circ} \mathrm{C}$, jeopardizing the quality of goat milk during storage (Table 2). At this temperature, 90.3\% of the isolates that harbored the apr gene also showed proteolytic activity, whereas $56.0 \%$ of isolates negative for apr showed proteolysis. Even though it is not possible to determine a statistical difference between such frequencies, this result indicates that the presence of apr can be associated with proteolysis at $7^{\circ} \mathrm{C}$. The isolates were also able to produce proteases at $25^{\circ} \mathrm{C}$ and $35^{\circ} \mathrm{C}$ (Table 2), demonstrating their spoilage activity under transport and processing conditions, and highlighting the need for contamination control in the early steps of production.

The present study demonstrated the ubiquity of Pseudomonas spp. in raw goat milk and their ability to produce proteolytic enzymes at different temperatures, 


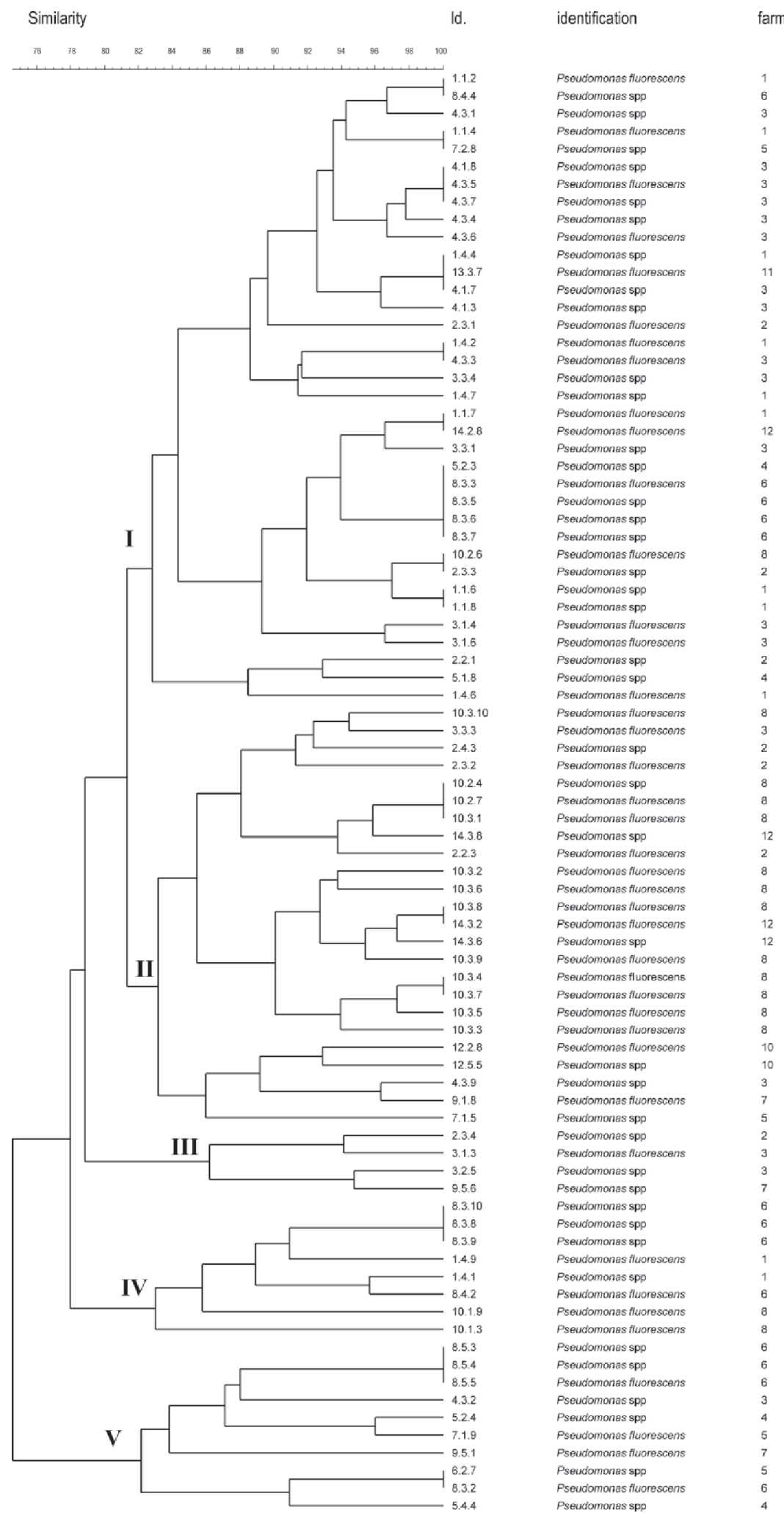

Figure 1. Dendrogram obtained by XbaI macro-restriction and pulsed-field gel electrophoresis of Pseudomonas isolates obtained from goat milk. Pulsotype was obtained considering $5 \%$ as the tolerance for the Dice similarity of bands, and the unweighted pair group method with arithmetic mean (UPGMA) was used for clustering and dendrogram construction. Id. = isolate code; identification indicates genus and species by PCR; farm = goat farm from which the isolate was obtained. Numerals I to V indicate clusters of isolates that shared approximately $82 \%$ similarity. 
Table 2. Frequencies of Pseudomonas spp. isolates obtained from goat milk that carried the alkaline protease gene $(a p r)$ gene and proteolytic activity after incubation at different temperatures

\begin{tabular}{|c|c|c|c|c|}
\hline \multirow[b]{2}{*}{ apr gene } & \multirow{2}{*}{$\begin{array}{c}\text { No. of } \\
\text { samples }\end{array}$} & \multicolumn{3}{|c|}{ Incubation temperature } \\
\hline & & $7^{\circ} \mathrm{C}$ & $25^{\circ} \mathrm{C}$ & $35^{\circ} \mathrm{C}$ \\
\hline Positive & 32 & 29 & 32 & 21 \\
\hline Negative & 50 & 28 & 50 & 43 \\
\hline
\end{tabular}

thus emphasizing the relevance of this genus as potential spoilage organism in the dairy chain. These findings indicate the need for proper control of contamination and growth of Pseudomonas spp. during production and storage of goat milk.

\section{ACKNOWLEDGMENTS}

This research was supported by CAPES (Coordenação de Aperfeiçoamento de Pessoal de Nível Superior, Brasília, DF, Brazil), CNPq (Conselho Nacional de Pesquisa Científica, Brasília, DF, Brazil), and FAPEMIG (Fundação de Amparo a Pesquisa do Estado de Minas Gerais, Belo Horizonte, MG).

\section{REFERENCES}

Arslan, S., A. Eyi, and F. Ozdemir. 2011. Spoilage potentials and antimicrobial resistance of Pseudomonas spp. isolated from cheeses. J. Dairy Sci. 94:5851-5856.

Bach, H. J., A. Hartmann, M. Schloter, and J. C. Munch. 2001. PCR primers and functional probes for amplification and detection of bacterial genes for extracellular peptidases in single strains and in soil. J. Microbiol. Methods 44:173-182.

Brasil. 2000. Instrução Normativa 37-Aprova o Regulamento Técnico de Identidade e Qualidade de Leite de Cabra. Diário Oficial da União, 08 de novembro de 2000 ed. MAPA, ed. Brasília, DF, Brazil.

Brasil. 2011. Instrução Normativa 62-Aprovar o Regulamento Técnico de Produção, Identidade e Qualidade do Leite tipo A, o Regulamento Técnico de Identidade e Qualidade de Leite Cru Refrigerado, o Regulamento Técnico de Identidade e Qualidade de Leite Pasteurizado e o Regulamento Técnico da Coleta de Leite Cru Refrigerado e seu Transporte a Granel. Diário Oficial da União. Brasil, Brasília, DF, Brazil.

Chambers, J. V. 2002. The Microbiology of Raw Milk. Pages 39-90 in Dairy Microbiology Handbook. R. K. Robinson, ed. John Wiley and Sons Inc., New York, NY.

Chen, L., R. M. Daniel, and T. Coolbear. 2003. Detection and impact of protease and lipase activities in milk and milk powders. Int. Dairy J. 13:255-275.

Chen, T. R., Q. K. Wei, and Y. J. Chen. 2011. Pseudomonas spp. and Hafnia alvei growth in UHT milk at cold storage. Food Contr. 22:697-701.

Dogan, B., and K. J. Boor. 2003. Genetic diversity and spoilage potentials among Pseudomonas spp. isolated from fluid milk products and dairy processing plants. Appl. Environ. Microbiol. 69:130138.

Downes, F. P., and K. Ito. 2001. Compendium of Methods for the Microbiological Examination of Foods. American Public Health Association, Washington, DC.
Dufour, D., M. Nicodeme, C. Perrin, A. Driou, E. Brusseaux, G. Humbert, J.-L. Gaillard, and A. Dary. 2008. Molecular typing of industrial strains of Pseudomonas spp. isolated from milk and genetical and biochemical characterization of an extracellular protease produced by one of them. Int. J. Food Microbiol. 125:188-196.

Fagundes, C. M., V. Fischer, W. P. Silva, N. Carbonera, and M. R. Araújo. 2006. Presence of Pseudomonas spp. in milking phases with different hygienic handling procedures and in refrigerated milk. Ciência Rural 36:568-572.

Haenlein, G. F. W. 2004. Goat milk in human nutrition. Small Rumin. Res. 51:155-163.

Hantsis-Zacharov, E., and M. Halpern. 2007. Culturable psychrotrophic bacterial communities in raw milk and their proteolytic and lipolytic traits. Appl. Environ. Microbiol. 73:7162-7168.

ISO. 2009. ISO/TS 11059:2009 (IDF/RM 225: 2009)-Milk and milk products: Method for the enumeration of Pseudomonas spp. International Organization for Standardization (ISO), Geneva, Switzerland.

Marchand, S., G. Vandriesche, A. Coorevits, K. Coudijzer, V. De Jonghe, K. Dewettinck, P. De Vos, B. Devreese, M. Heyndrickx, and J. De Block. 2009. Heterogeneity of heat-resistant proteases from milk Pseudomonas species. Int. J. Food Microbiol. 133:68-77.

Martins, M. L., E. F. de Araujo, H. C. Mantovani, C. A. Moraes, and M. C. D. Vanetti. 2005. Detection of the apr gene in proteolytic psychrotrophic bacteria isolated from refrigerated raw milk. Int. J. Food Microbiol. 102:203-211.

Pandya, A. J., and K. M. Ghodke. 2007. Goat and sheep milk products other than cheeses and yoghurt. Small Rumin. Res. 68:193-206.

Perin, L. M., P. M. Moraes, M. V. Almeida, and L. A. Nero. 2012. Interference of storage temperatures in the development of mesophilic, psychrotrophic, lipolytic and proteolytic microbiota of raw milk. Semina 33:333-342.

Pinto, C. L. O. P., M. L. Martins, and M. C. D. Vanetti. 2006. Microbial quality of raw refrigerated milk and isolation of psychrotrophic proteolytic bacteria. Food Sci. Technol. (Campinas.) 26:645-651.

Quigley, L., O. O'Sullivan, C. Stanton, T. P. Beresford, R. P. Ross, G. F. Fitzgerald, and P. D. Cotter. 2013. The complex microbiota of raw milk. FEMS Microbiol. Rev. 37:664-698.

Rajmohan, S., C. E. R. Dodd, and W. M. Waites. 2002. Enzymes from isolates of Pseudomonas fluorescens involved in food spoilage. J. Appl. Microbiol. 93:205-213.

Samarzija, D., S. Zamberlin, and T. Pogacic. 2012. Psychrotrophic bacteria and their negative effects on milk and dairy products quality. Mljekarstvo 62:77-95.

Scarpellini, M., L. Franzetti, and A. Galli. 2004. Development of PCR assay to identify Pseudomonas fluorescens and its biotype. FEMS Microbiol. Lett. 236:257-260.

Scintu, M. F., and G. Piredda. 2007. Typicity and biodiversity of goat and sheep milk products. Small Rumin. Res. 68:221-231.

Simões, M., L. C. Simões, and M. J. Vieira. 2010. A review of current and emergent biofilm control strategies. LWT - . Food Sci. Technol. (Campinas.) 43:573-583.

Sorhaug, T., and L. Stepaniak. 1997. Psychrotrophs and their enzymes in milk and dairy products: Quality aspects. Trends Food Sci. Technol. 8:35-41.

Spilker, T., T. Coenye, P. Vandamme, and J. J. LiPuma. 2004. PCRBased assay for differentiation of Pseudomonas aeruginosa from other Pseudomonas species recovered from cystic fibrosis patients. J. Clin. Microbiol. 42:2074-2079.

Wehr, H. M., and J. F. Frank. 2004. Standard Methods for the Examination of Dairy Products. American Public Health Association, Washington, DC.

Yamazi, A. K., T. S. Moreira, V. Q. Cavicchioli, R. C. Konrad Burin, and L. A. Nero. 2013. Long cold storage influences the microbiological quality of raw goat milk. Small Rumin. Res. 113:205-210. 